\title{
Leadership \& Professional Development: Make a Friend Before You Need One
}

\author{
Sanjay Saint, MD, $\mathrm{MPH}^{1,2 *}$, Vineet Chopra, MD, MSc $\mathrm{M}^{1,2}$
}

'Patient Safety Enhancement Program, Veterans Affairs Ann Arbor Healthcare System and University of Michigan Health System, Ann Arbor, Michigan; ${ }^{2}$ Division of Hospital Medicine, University of Michigan Health System, Ann Arbor, Michigan.

"Takers believe in a zero-sum world, and they end up creating one where bosses, colleagues and clients don't trust them. Givers build deeper and broader relationships-people are rooting for them instead of gunning for them."

-Adam Grant

To succeed in a hospital, leaders need a generous supply of social and political capital. House officers learn this very quickly, especially when they are relying on other members of the healthcare team to obtain tests and studies for their patients and calling for specialty consultations. To be successful and efficient, building relationships and trust is key. Such capital, unfortunately, takes time to develop. Therefore, healthcare leaders and clinicians at all levels of training need to make an everyday investment of goodwill and friendliness with those they encounter. The dividends may be slow in coming, but they are substantial and sustained. Friends give you the benefit of the doubt-and help you when you are most in need.

Having friends (or friendly colleagues) at work is beneficial both professionally and personally. The benefits of social interactions have been studied for years and even more so in recent times with the dramatic increase in the use of handheld devices. Eye contact between casual acquaintances passing each other in the hallway is replaced with eyes focused downward on smartphones. The result? We are becoming more socially isolated. Our personal solution? When we see professional colleagues (or patients and families in the hallways of our hospital), we nod in acknowledgement with appropriate eye contact and say "Good morning" or "Hello" even if we don't know them-even if their eyes are focused on their devices as they walk past you in the hallway. You get a gold star if you

*Corresponding Author: Sanjay Saint, MD, MPH; Email: saint@med.umich.edu; Telephone: 734-615-8341; Twitter: @sanjaysaint.

Received: February 3, 2020; Accepted: February 4, 2020

(C) 2020 Society of Hospital Medicine DOI 10.12788/jhm.3392 remember the names of the professional colleagues you see frequently in the hallways or around the hospital.

This isn't soft science; it's backed by hard data. When we conduct site visits of different hospitals around the country to help them improve their care quality and performance, we informally divide hospitals into two groups: The "How ya doin'?" hospitals vs the "Rec-lgnore" hospitals (in which employees recognize a colleague in the hallway but choose to not acknowledge them). Most prefer to work at a "How ya doin'?" hospital. Being friendly has been linked to increased team spirit and morale, knowledge sharing, trust, prevention of burnout, and sense of a positive working environment. It also makes you feel better about yourself-and makes other people feel similarly as well.

We'll share an example from a search for a new department chair. The dean went on reverse site visits to meet the two finalists in their home institutions and asked them for tours of their hospitals. Candidate A walked around and it seemed like everyone knew her. She smiled and said hello to the people she came in contact with during the tour. Not so for candidate B-just the opposite. Guess which candidate the dean hired?

Put away your phone, interact with your colleagues, and learn to make small talk, and not just with your supervisors or peers. Chitchat is an important "social lubricant," fostering a sense of community and teamwork. It helps bring down the divides that come from organizational hierarchies. It helps endear you to your staff.

Developing a reputation as a nice person who is quick with a smile and even quicker with a "How ya doin'?" pays off in the end. This reputation also makes it easier to give bad news, something that all leaders must do at some point. So make a friend before you need one_-it usually will pay dividends.

Disclosures: Drs Saint and Chopra are coauthors of the book, Thirty Rules for Healthcare Leaders, from which this article is adapted. Both authors have no other relevant conflicts of interest. 